Article

\title{
Ensemble Learning of Multi-Source Satellite Sensors Dataset for Estimating Forest Biomass in New England Region
}

\author{
Ram C. Sharma \\ 1 Department of Informatics, Tokyo University of Information Sciences, 4-1 Onaridai, Wakaba-ku, \\ Chiba 265-8501, Japan \\ * Correspondence: sharma@rsch.tuis.ac.jp; Tel.: +81-43-236-1408; Fax: +81-43-236-2215
}

Received: date; Accepted: date; Published: date

\begin{abstract}
This paper presents ensemble learning of multi-source satellite sensors dataset to obtain better predictive performance of the forest biomass. Spectral, spectral-indices, and spectral-textural features were generated from two optical satellite sensors, Landsat 8 Operational Land Imager (OLI) and Sentinel-2 Multispectral Instrument (MSI). In addition, two radar satellite sensors, Sentinel-1 Cband Synthetic Aperture Radar (CSAR), and Advanced Land Observing Satellite (ALOS-2) Phased Array type L-band Synthetic Aperture Radar (PALSAR-2) were utilized to generate backscattering and backscattering-textural features. The plot-wise above ground biomass data available from five forests in New England region were utilized. Ensemble learning of multi-source satellite sensors dataset was carried out by employing four machine learning regressors namely, Support Vector Machines (SVM), Random Forests (RF), Gradient Boosting (GB), and Multilayer Perceptron (MLP). A five-fold cross-validation method was used to evaluate predictive performance of the multisource satellite sensors. The integration of multi-source satellite features, comprising of spectral, spectral-indices, backscattering, spectral-textural, and backscattering-textural information, through ensemble learning and cross-validation approach implemented in the research showed promising results $\left(\mathrm{R}^{2}=0.81\right.$, $\left.\mathrm{RMSE}=46.2 \mathrm{Mg} / \mathrm{ha}\right)$ for the estimation of plots-level forest biomass in New England region.
\end{abstract}

Keywords: Forests; biomass; ALOS-2 PALSAR-2; Sentinel-1 CSAR; Sentinel-2 MSI; Landsat 8 OLI; ensemble learning.

\section{Introduction}

Forest biomass is a key parameter for monitoring of deforestation and degradation of forests. Satellite remote sensing has a huge potential of estimation and mapping of forest biomass at a broad scale. Researchers have utilized different kinds of aerial and satellite imagery for the estimation and mapping of forest biomass, which can be categorized as follows:

(i) Optical data: A combination of multispectral vegetation indices and texture images from high spatial resolution imagery has been utilized for estimating forest biomass (Freitas et al., 2005; Silleos et al., 2006; Champion et al., 2008; Attarchi and Gloaguen, 2014). In addition, multiangular remote sensing data from moderate-resolution optical satellites is another information for retrieving forest structural information (Chen et al., 2003; Widlowski et al., 2004; Ponzoni et al., 2010; Chopping et al., 2011).

(ii) Radar data: Synthetic Aperture Radar (SAR) data are reported to be sensitive to forest structure and biomass due to its capacity to penetrate into tree crowns (Sandberg et al., 2011; 
Saatchi and Marlier, 2011). However, they are noisy due to sensitivity to terrain and moisture contents (Kasischke et al., 2009; Lucas et al., 2010) and complex backscattering mechanisms involves with crowns, stems, and soils (Richards et al., 1987; Freeman and Durden, 1998). Still, highly penetrable L-and P-bands also saturate over dense forests due to multiple interruptions and attenuation of the signals (Gonzalez et al., 2010; Mermoz et al., 2015; Yu and Saatchi, 2016).

(iii) Lidar data: Airborne lidar scanning has shown promising results at local scales (Stephens et al., 2012; Kankare et al., 2013; Maselli et al., 2014; Cao et al., 2018). Spaceborne lidar has been expected for improved estimates of forest biomass (Hu et al., 2016; Nelson et al., 2017).

Machine learning of satellite data features with field plots data has become a commonly used technique for the estimation and mapping of forest biomass (Ghosh and Behera, 2018). A number of machine learning regressors have been employed for this purpose. Multiple linear regression is one of the heavily used technique by many researchers (Carreiras et al., 2012, Basuki et al., 2013). Random Forests $(\mathrm{RF})$, ensemble of decision trees, which are built by splitting the attributes of the data and averaging the output value of all trees, is a powerful algorithm for learning complex and highly nonlinear relationships (Breiman, 2001). The RF regressor has been used by many studies for the estimation of forest biomass (Mutanga et al., 2012; Otgonbayar et al., 2019; Zeng et al., 2019). To minimize the over-fitting problem of decision trees, the Gradient Boosting (GB) technique, that reduces different loss functions and constraints the tree building (Friedman, 2002), has been employed for improved estimation of forest biomass (Dube and Mutanaga, 2014; Filippi et al., 2014; Güneralp et al., 2014). Some researchers have utilized Support Vector Machines (SVM) regressor, which tries to find a function that deviates from the target variable by a value no greater than a certain threshold (Chang and Lin, 2002), for the estimation of forest biophysical variables including aboveground biomass (Chen and Hay, 2011; Marabel et al., 2013; Singh et al., 2015; Wan et al., 2018). More recently, artificial neural network such as Multilayer Perceptron (MLP), which consists of an input layer, hidden layer(s) and an output layer, and uses a non-linear activation function (Cybenko, 1989), has shown promising results on the estimation of forest structural parameters including biomass (Foody et al., 2011; Santi et al., 2017; Chen et al., 2019).

Despite the availability of a number of aerial and satellite sensors data and machine learning regressors, estimation and mapping of forest biomass is a challenging task. The major objective of this research is to present an improved estimation of biomass by harnessing the following four satellite sensors dataset, which are available freely.

(i) National Aeronautics and Space Administration (NASA) and the United States Geological Survey (USGS) Landsat 8 Operational Land Imager (OLI)

(ii) European Space Agency (ESA) Sentinel-2 Multispectral Instrument (MSI)

(iii) ESA Sentinel-1 C-band Synthetic Aperture Radar (CSAR)

(iv) Japan Aerospace Exploration Agency (JAXA) Advanced Land Observing Satellite (ALOS-2) Phased Array type L-band Synthetic Aperture Radar (PALSAR-2) 
This research also assesses the potential of ensemble learning of the multi-source satellite sensors dataset for estimating plots-level biomass by employing the following four machine learning regressors:

(i) Support Vector Machines (SVM)

(ii) Random Forests (RF)

(iii) Gradient Boosting Trees (GB)

(iv) Artificial Neural Networks-Multilayer Perceptron (MLP)

\section{Materials and Methods}

\subsection{Study Area}

Plot-wise database available for five forests in New England region were utilized in the research (Cook et al., 2011). The location of the study sites and their forest types are described in Table 1.

Table 1. Description of the study sites (Cook et al., 2011).

\begin{tabular}{llll}
\hline Study sites & Geo-location & Forest types \\
\hline (i) $\quad$ Harvard Forest, Massachusetts & $42.53^{\circ},-72.17^{\circ}$ & $\begin{array}{c}\text { Deciduous } \\
\text { hardwoods }\end{array}$ \\
(ii) $\quad$ Howland Research Forest, Maine & $45.20^{\circ},-68.73^{\circ}$ & Mixed conifers \\
& & & and hardwoods \\
(iii) $\quad$ Hubbard Brook Experimental Forest, & $43.56^{\circ},-71.45^{\circ}$ & Deciduous \\
& New Hampshire & & hardwoods \\
(iv) $\quad$ Bartlett Experimental Forest, New & $44.04^{\circ},-71.16^{\circ}$ & Deciduous \\
& Hampshire & & hardwoods \\
(v) & Penobscott Experimental Forest, Maine & $44.86^{\circ},-68.65^{\circ}$ & Mixed conifers \\
& & & and hardwoods \\
\hline
\end{tabular}

The location map of the study area and distribution of sample plots is shown in Figure 1. 


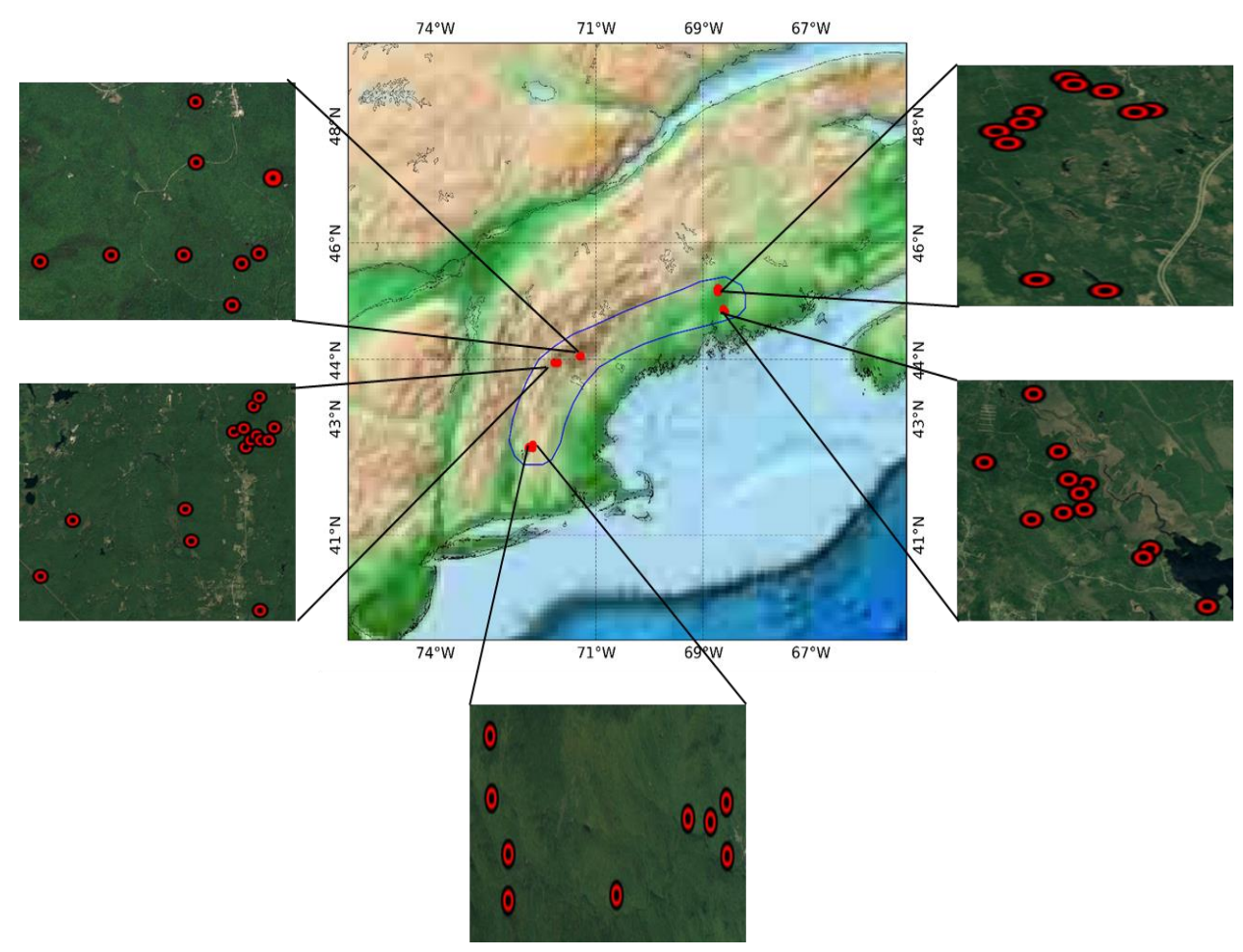

Figure 1. Location map of the study area in New England region and distribution of sample plots in five study sites.

\subsection{In situ biomass data}

The database consists of 59 sample plots in total, each of 1 ha size. The above ground biomass were calculated with diameter at breast height greater than $10 \mathrm{~cm}$ using the allometric function (Jenkins et al., 2004) (Equation 1). In Equation 1, the Above Ground Biomass (B) in kg was calculated by the exponential function of Diameter at Breast Height ( $\mathrm{dbh}$ ) in $\mathrm{cm}$. The species-specific parameters, a and $b$, varied from -0.712 to -2.54 and 1.7 to 2.48 respectively.

$$
B=\exp ^{a+(b \times \ln (d b h))}
$$

Plot-wise summary data (Megagrams per hectare) consisting of three structural parameters ( $\mathrm{dbh}$, tree height, and above ground biomass) were extracted from the database. In five forests, the above ground biomass ranged from 0.0017 to $362.846 \mathrm{Mg} / \mathrm{ha}$ with mean value of $178.43 \mathrm{Mg} / \mathrm{ha}$.

\subsection{Processing of Satellite Data}

All Landsat 8 OLI, Sentinel-2 MSI, Sentinel-1 CSAR, and ALOS-2 PALSAR-2 data available in 2017 for the New England region were acquired and processed. For the Landsat 8 and Sentinel-2 data, the top-of-atmosphere (TOA) reflectance were calculated by utilizing the rescaling coefficients found in the metadata file, and the cloudy pixels were masked out by using pixel-wise quality assessment (QA) band available for each scene. Five spectral bands (blue, green, red, near infrared, and shortwave infrared) were extracted from the Landsat 8 OLI data and six spectral bands (blue, green, red, red edge, near infrared, and shortwave infrared) were extracted from the Sentinel-2 MSI data. For each scene, six broad-band vegetation indices, as shown in Table 2, were also calculated.

Table 2. List of vegetation indices calculated based on reflectance at Blue (B), Green (G), Red (R), and Near infrared $(\mathrm{N})$. 


\begin{tabular}{|c|c|c|c|}
\hline \multicolumn{2}{|c|}{ Vegetation indices } & \multirow{2}{*}{$\begin{array}{l}\text { Formula } \\
2.5 \times \frac{N-R}{(N+6 \times R-7.5 \times B)+1}\end{array}$} & \multirow{2}{*}{$\begin{array}{l}\text { References } \\
\text { Huete et al., } 2002\end{array}$} \\
\hline 1) & Enhanced Vegetation Index (EVI) & & \\
\hline 2) & Green Normalized Difference & $N-G$ & Gitelson and Merzlyak, \\
\hline & Vegetation Index (GNDVI) & $\overline{N+G}$ & 1998 \\
\hline 3) & Green Red Vegetation Index (GRVI) & $\frac{G-R}{G+R}$ & Falkowski et al., 2005 \\
\hline 4) & $\begin{array}{l}\text { Normalized Difference Vegetation } \\
\text { Index (NDVI) }\end{array}$ & $\frac{N-R}{N+R}$ & Rouse et al., 1974 \\
\hline 5) & $\begin{array}{l}\text { Structure Insensitive Pigment } \\
\text { Index ( SIPI ) }\end{array}$ & $\frac{N-B}{N-R}$ & Penuelas et al., 1995 \\
\hline 6) & $\begin{array}{l}\text { Visible Atmospherically Resistant Index } \\
\text { (VARI) }\end{array}$ & $\frac{G-R}{G+R-B}$ & Gitelson, et al., 2002 \\
\hline
\end{tabular}

The multi-temporal data (spectral bands and vegetation indices) were composited by calculating five percentile values $(0,25,50,75$, and 100) pixel by pixel to obtain a continuous dataset in spite of the clouds. Twenty-six Haralick's textures (Haralick et al., 1973) were also calculated using the maximum value (percentile 100) composite of the NDVI. The Sentinel-2 feature images including textures with spatial resolutions of $10-60 \mathrm{~m}$ were resampled into $30 \mathrm{~m}$ using the bilinear interpolation method to combine with Landsat 8 data.

Sentinel-1 CSAR Ground Range Detected (GRD) products and global $25 \mathrm{~m}$ Resolution PALSAR2 Mosaic Dataset of were acquired and processed. The Sentinel-1 CSAR and ALOS-2 PALSAR-2 images were processed for radiometric calibration (sigma naught). The muli-temporal images were composited by calculating five percentile values $(0,25,50,75$, and 100) pixel by pixel to capture various backscattering characteristics of the forest, which is very sensitive to roughness and moisture conditions. Twenty six Haralick's textures were also calculated using the mean value (percentile 50) composite images for both polarizations (HH and HV for PALSAR-2 and VV and VH for CSAR). The resulting images including the texture images were resampled into $30 \mathrm{~m}$ to combine with optical data.

\subsection{Machine learning and cross-validation}

High-dimensional feature images, consisting of spectral, spectral-indices, spectral-textural, backscattering, and backscattering-textural characteristics of the forests, were generated as shown by Table 3.

Table 3. Description of the high dimensional features generated.

\begin{tabular}{ccccccc}
\hline Satellite Sensors & Backscattering & Spectral & Indices & Textural & $\begin{array}{c}\text { Temporal } \\
\text { (Percentiles) }\end{array}$ & Sub-total \\
\hline Sentinel-1 CSAR & 2 & - & - & $17 \times 2$ & 5 & $2 \times 5+34=44$ \\
ALOS-2 PALSAR-2 & 2 & - & - & $17 \times 2$ & 5 & $2 \times 5+34=44$ \\
Landsat 8 OLI & - & 5 & 6 & $17 \times 1$ & 5 & $11 \times 5+17=72$ \\
Sentinel-2 MSI & - & 6 & 6 & $17 \times 1$ & 5 & $12 \times 5+17=77$ \\
\hline \multicolumn{7}{c}{ Total } \\
\hline
\end{tabular}

Mean pixel values using all pixels $(3 \times 3$ pixels $\sim 1$ ha) covered by the sample plots were extracted and features dataset was prepared for the machine learning. According to the method described by Sharma et al. (2017), 5-fold cross-validation approach was employed to assess performance of all satellite sensors. Inside the cross-validation loop, features were ranked based on univariate statistical test and important set of features were selected by the criteria of Root Mean Square Error (RMSE). This procedure was repeated for each individual satellite sensors dataset and their different 
combinations. The predictions with the optimum number of features across four machine learning regressors were combined by average ensembling of the predictions. The performance of individual machine learning regressors and ensembling of them was reported in terms of Coefficient of determination $\left(\mathrm{R}^{2}\right)$ and RMSE through 5 -fold cross-validation approach.

\section{Results}

\subsection{Performance of individual satellite sensors}

As shown in Figure 2, out of four machine learning regressors employed, MLP performed better than others in most of the cases. However, ensembling of them provided better accuracy than MLP in all cases except PALSAR-2 (without textures). Usually individual satellite sensors with texture features performed better than without texture features. Overall, Landsat 8 OLI showed highest accuracy $\left(R^{2}=0.76\right.$, RMSE $\left.=52.1 \mathrm{Mg} / \mathrm{ha}\right)$ followed by Sentinel-2 MSI $\left(R^{2}=0.57, \mathrm{RMSE}=65.1 \mathrm{Mg} / \mathrm{ha}\right)$ and Sentinel-1 CSAR $\left(\mathrm{R}^{2}=0.51, \mathrm{RMSE}=75.1 \mathrm{Mg} / \mathrm{ha}\right)$.

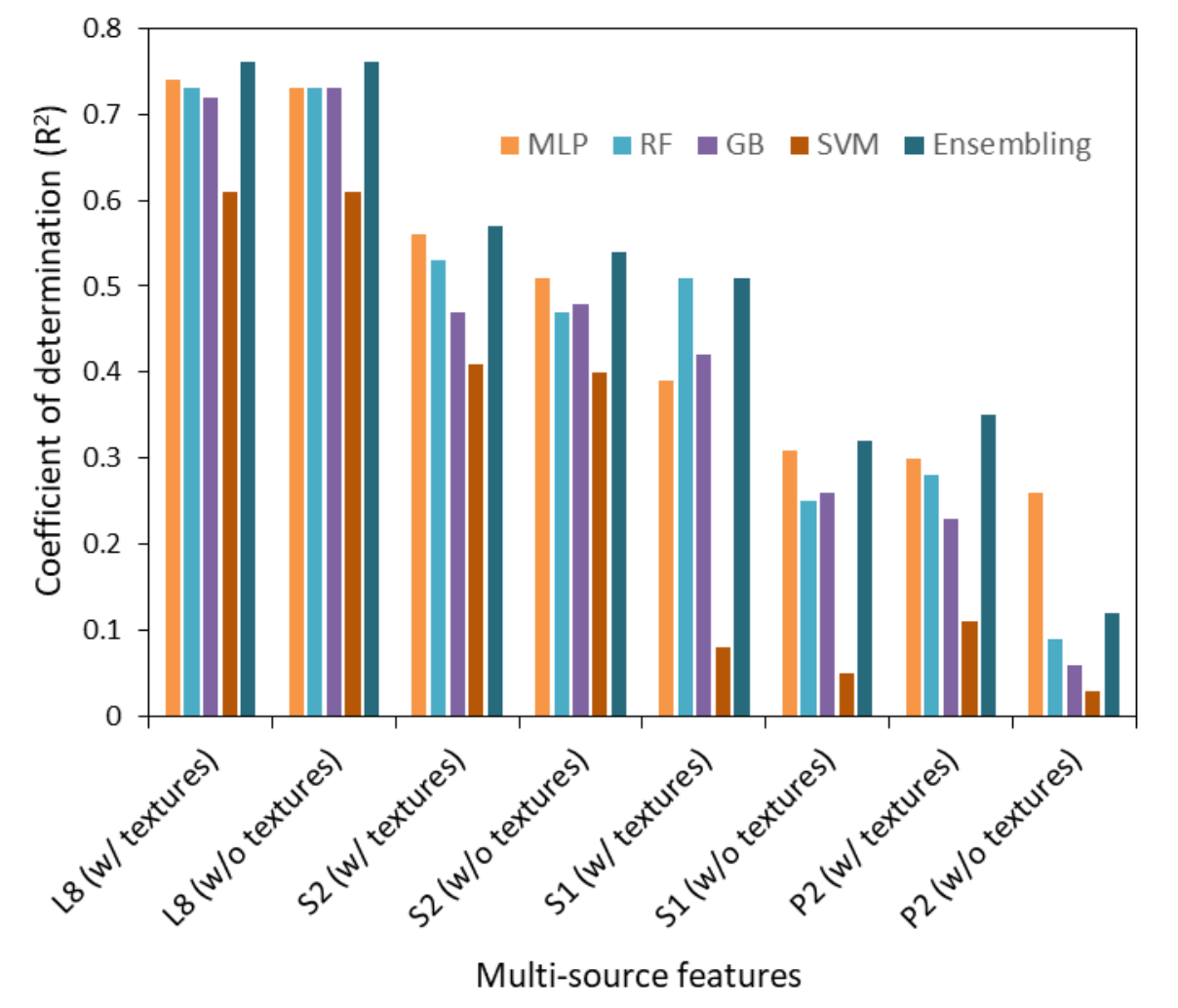

Figure 2. Performance of individual satellite sensors.

\subsection{Performance of combined satellite sensors}

For different combination of satellite sensors as shown in Figure 3, the MLP started to perform as better as ensembling with the increase in features. In addition, textural features did not show significant improvement when large number of multi-spectral and backscattering features were available. Combination of all four satellite sensors dataset provided slightly better $\left(\mathrm{R}^{2}=0.81\right.$, RMSE $=46.2 \mathrm{Mg} / \mathrm{ha})$ performance than the combination of three satellite sensors $\left(\mathrm{R}^{2}=0.81\right.$, RMSE $=46.4$ $\mathrm{Mg} / \mathrm{ha})$. 


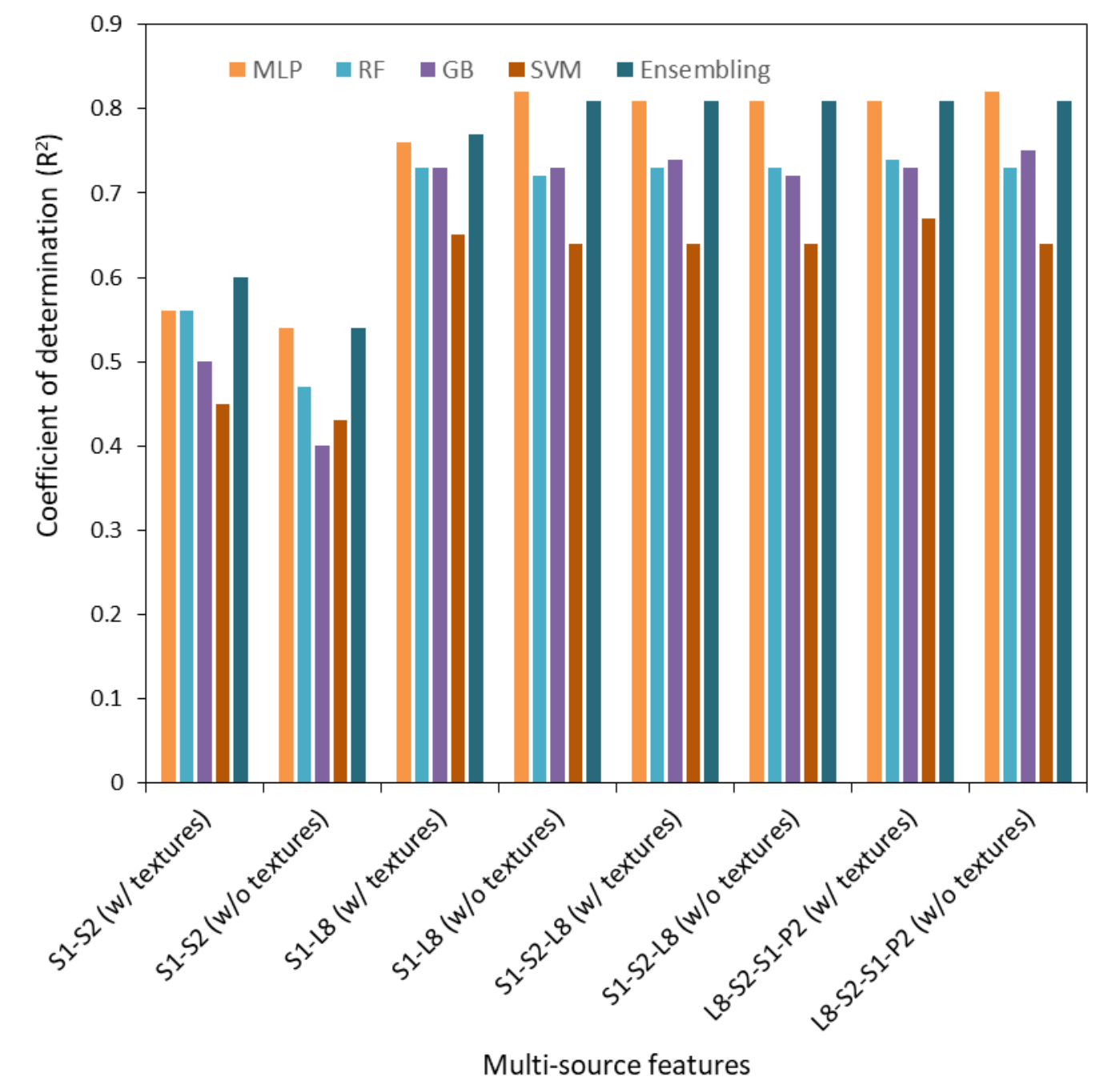

Figure 3. Performance of individual satellite sensors.

The cross-validation results obtained from the ensemble learning of multi-source satellite sensors are summarized in Table 4.

Table 4. Cross-validation results

\begin{tabular}{lcrrr}
\hline & \multicolumn{2}{c}{ With textures } & \multicolumn{2}{c}{ Without textures } \\
\cline { 2 - 5 } \multicolumn{1}{c}{ Satellite sensors } & $\mathrm{R}^{2}$ & RMSE & $\mathrm{R}^{2}$ & RMSE \\
\cline { 2 - 5 } L8 & 0.76 & 52.1 & 0.76 & 52.2 \\
S2 & 0.57 & 65.1 & 0.54 & 66.8 \\
S1 & 0.51 & 75.1 & 0.32 & 81.3 \\
P2 & 0.35 & 80.0 & 0.12 & 91.0 \\
S1-S2 & 0.60 & 64.5 & 0.54 & 67.2 \\
S1-L8 & 0.77 & 51.2 & 0.81 & 48.8 \\
S1-S2-L8 & 0.81 & 46.4 & 0.81 & 47.3 \\
L8-S2-S1-P2 & 0.81 & 46.2 & 0.81 & 46.6 \\
\hline
\end{tabular}

The performance of individual satellite sensors dataset obtained through the ensemble learning and cross validation approach has been shown in Figure 4 . 


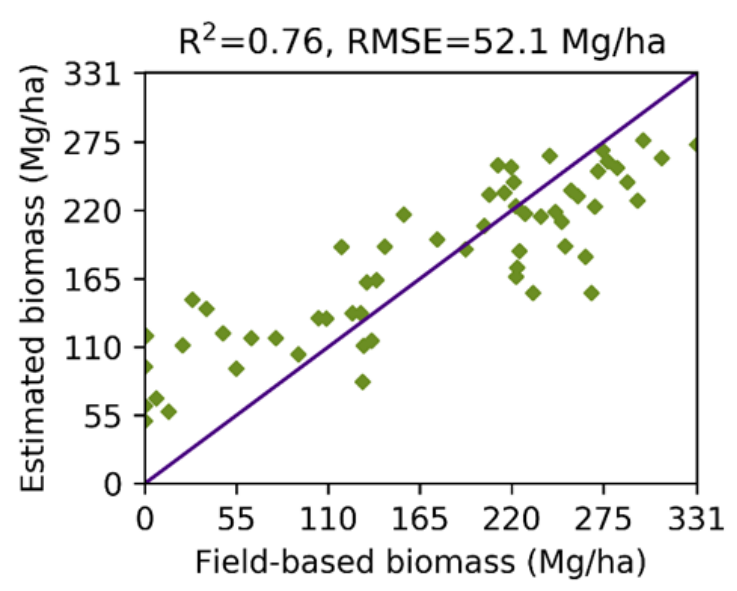

(a)

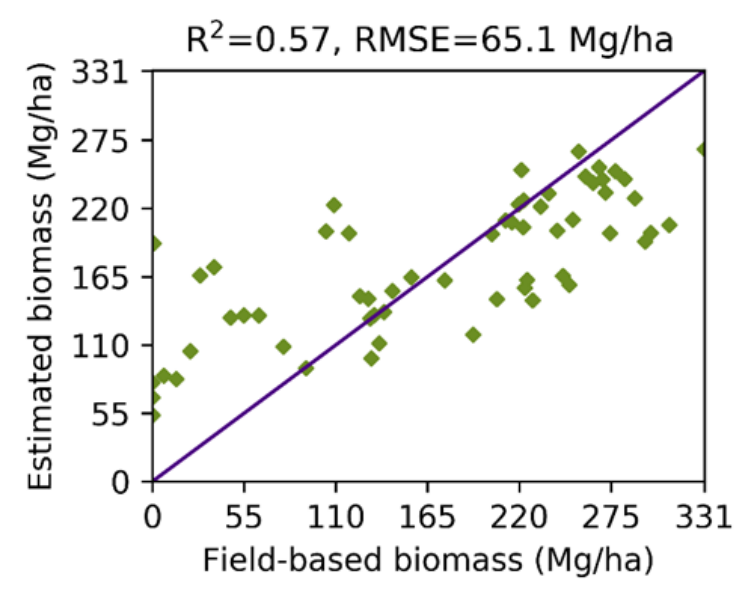

(b)

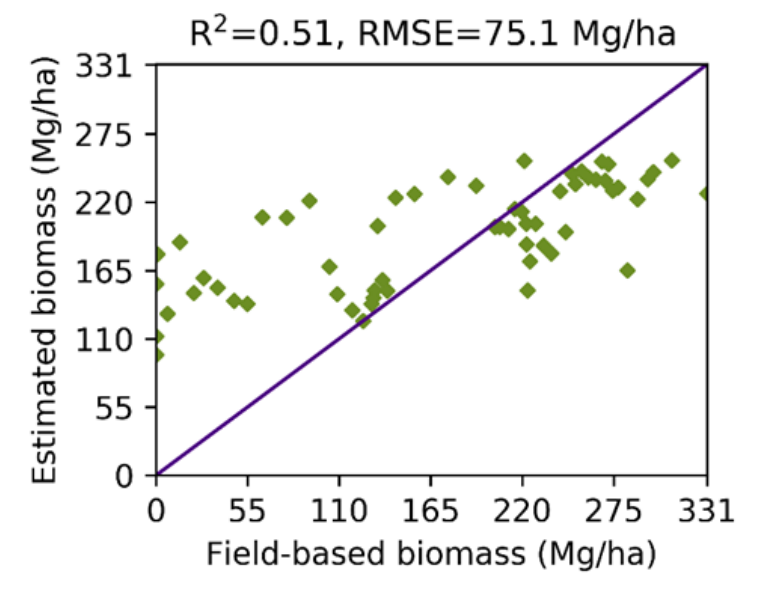

(c)

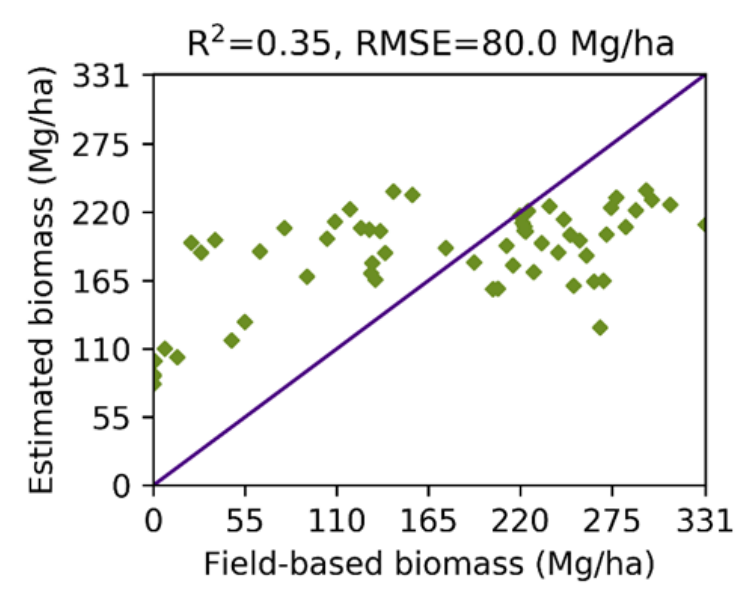

(d)

Figure 4. Performances of four individual satellite sensors: (a) Landsat 8 OLI, (b) Sentinel-2 MSI, (c) Sentinel-1 CSAR, (d) ALOS-2 PALSAR-2

The performances of combinations of different satellite sensors dataset through ensemble learning and cross validation approach has been shown in Figure 5. 


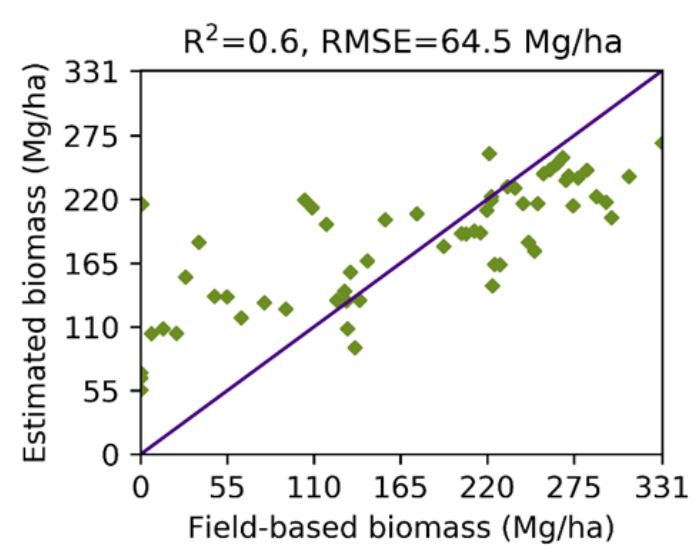

(a)

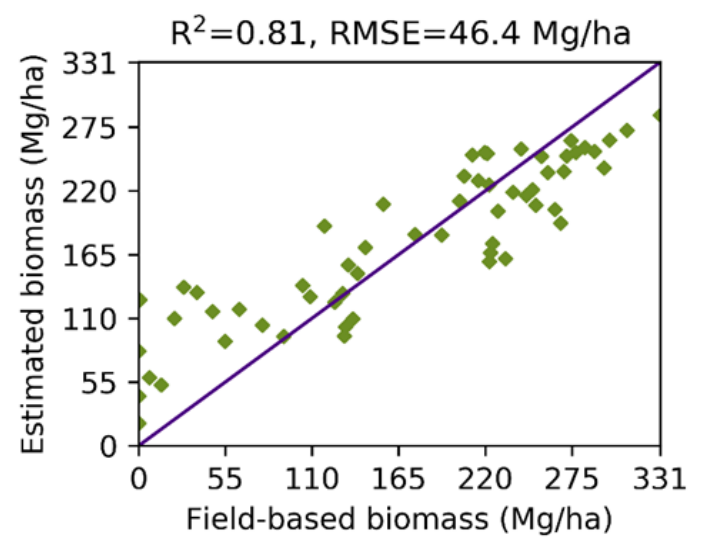

(c)

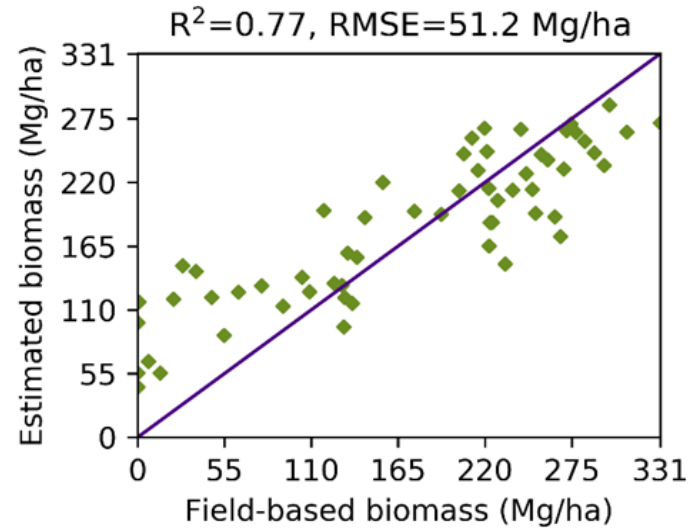

(b)

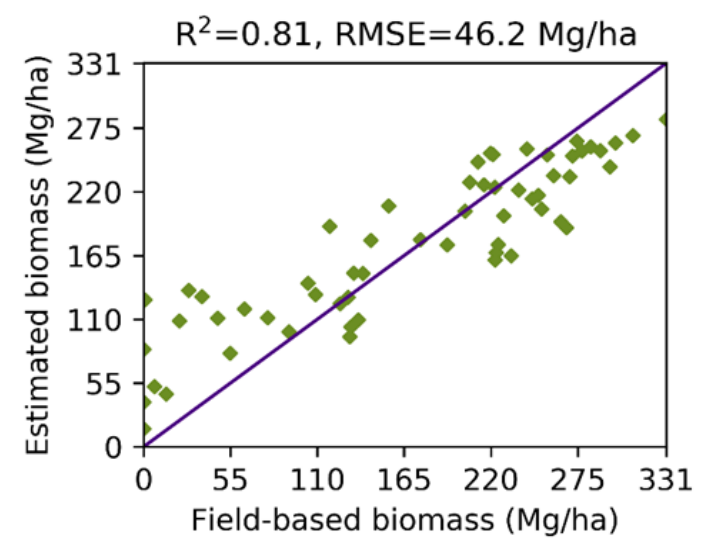

(d)

Figure 5. Performances of different combinations of satellite sensors: (a) Sentinel-1 CSAR and Sentinel-2 MSI (b) Sentinel-1 CSAR and Landsat 8 OLI (c) Sentinel-1 CSAR, Sentinel-2 MSI and Landsat 8 OLI (d) Sentinel-1 CSAR, Sentinel-2 MSI, Landsat 8 OLI and ALOS-2 PALSAR-2

The number of optimum features selected by each machine learning regressor for individual satellite sensors and their combinations has been shown in Figure 6. Though MLP and SVM regressors were mostly features hungry regressors, performance of SVM was inferior to others and the superiority of MLP with a large number of features requirement was noted. 


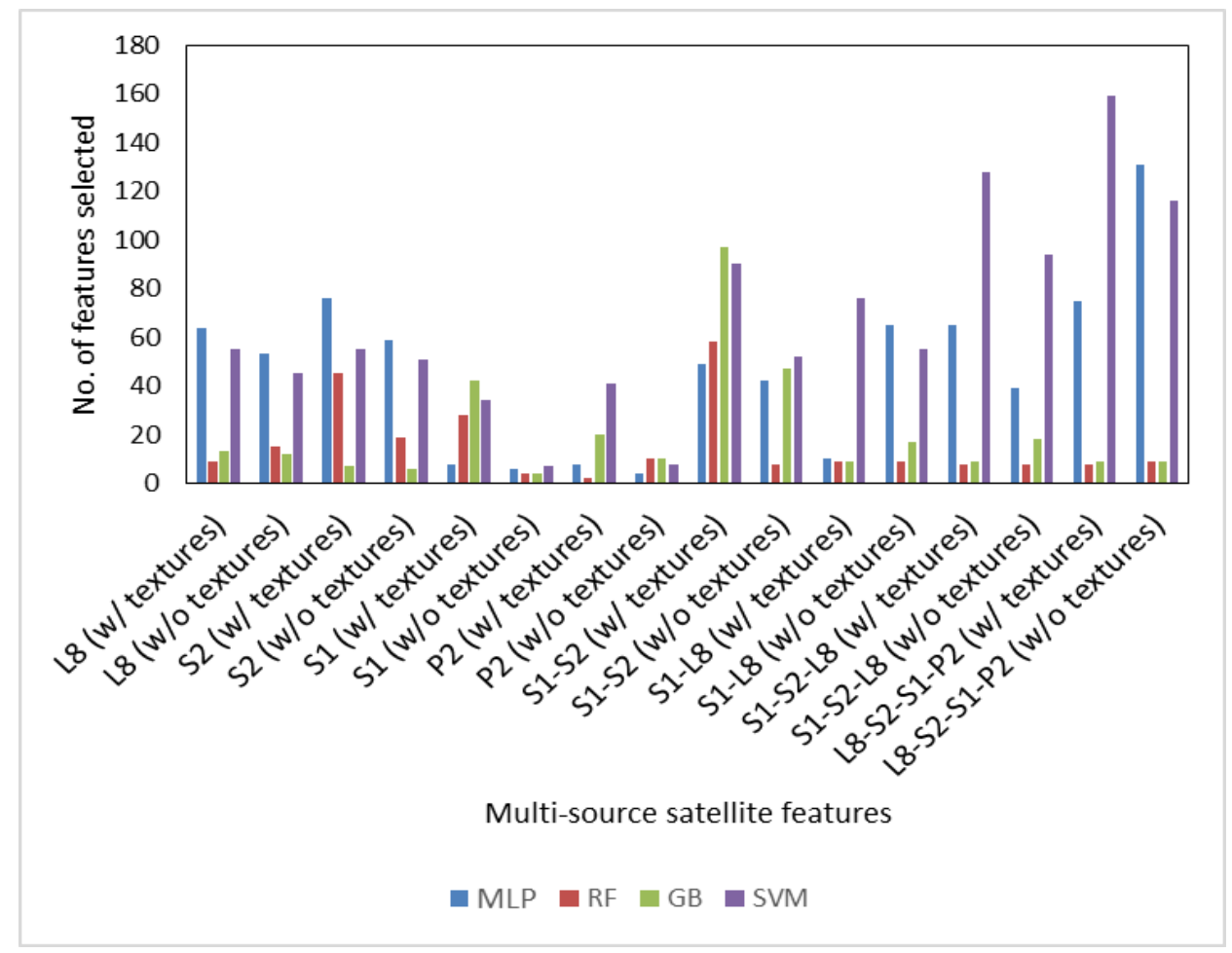

Figure 6. Optimum number of features selected and utilized for individual satellite sensors and their different combinations

\section{Discussion}

Saturation of remotely sensed signals over a multi-storied and dense canopies is a major issue (Lu et al., 2006; Rodríguez-Veiga et al., 2017). Previous researches have reported better performance of SAR data over the multispectral data (Englhart et al., 2011; Domingues et al., 2020). However, backscattering signals obtained from forest canopy is noisy due to complex backscattering mechanisms and sensitivity to roughness and moisture conditions (Huang et al., 2015). For the New England region in 2017, many temporal data were available for Landsat 8 OLI, Sentinel-2 MSI, and Sentinel-1 CSAR; whereas only a single data was available for PALSAR-2. Availability of dense timeseries data from the Sentinel-1 CSAR should have made it more sensitive to the forest biomass than PALSAR-2 data due to possible suppression of the noises.

Similar to this research, previous researches also showed improved estimates of the forest biomass by the addition of textural features (Sarker et al., 2011; Eckert et al., 2012; Kelsey and Neff, 2014; Phua et al., 2017; Berninger et al., 2018). However, it was noticed that contribution of the textural features decreased when the number of multi-spectral and backscattering features were high. The biomass database utilized in the research was based on field measurements conducted in 2009. It is one of the highest quality database openly available in the world. There should be more or less uniform changes in the above ground biomass across the sampling plots over 8 years. Therefore, remote sensing signals of 2017 are still able to see plot wise variation of biomass through regression analysis. Nevertheless, synchronization of the satellite data with the field plots data should further improve the estimates of biomass.

\section{Conclusions}

In this research, dense features dataset, comprising of spectral, spectral-indices, backscattering, spectral-textural, and backscattering-textural information, was generated from multi-source satellite sensors. The ensemble learning of multi-source satellite sensors dataset and cross-validation approach implemented in the research showed high potential $\left(\mathrm{R}^{2}=0.81, \mathrm{RMSE}=46.2 \mathrm{Mg} / \mathrm{ha}\right)$ for the 
estimation of plots-level forest biomass in New England region. It is expected that these results are useful to other regions as well.

Acknowledgments: Sentinel-1 and -2 data were available from European Space Agency (ESA) Copernicus program. Landsat 8 data were available from the United States Geological Survey (USGS). ALOS-2 data have been supplied by Japan Aerospace Exploration Agency (JAXA).

Funding: This research received no funding.

\section{References}

1. Attarchi, S.; Gloaguen, R. Improving the Estimation of Above Ground Biomass Using Dual Polarimetric PALSAR and ETM+ Data in the Hyrcanian Mountain Forest (Iran). Remote Sensing 2014, 6, 3693-3715, doi:10.3390/rs6053693.

2. Basuki, T.M.; Skidmore, A.K.; Hussin, Y.A.; Van Duren, I. Estimating Tropical Forest Biomass More Accurately by Integrating ALOS PALSAR and Landsat-7 ETM+ Data. International Journal of Remote Sensing 2013, 34, 4871-4888, doi:10.1080/01431161.2013.777486.

3. Berninger, A.; Lohberger, S.; Stängel, M.; Siegert, F. SAR-Based Estimation of Above-Ground Biomass and Its Changes in Tropical Forests of Kalimantan Using L- and C-Band. Remote Sensing 2018, 10, 831, doi:10.3390/rs10060831.

4. Breiman, L. Random Forests. Machine Learning 2001, 45, 5-32, doi:10.1023/A:1010933404324.

5. Cao, L.; Pan, J.; Li, R.; Li, J.; Li, Z. Integrating Airborne LiDAR and Optical Data to Estimate Forest Aboveground Biomass in Arid and Semi-Arid Regions of China. Remote Sensing 2018, 10, 532, doi:10.3390/rs10040532.

6. Carreiras, J.M.B.; Vasconcelos, M.J.; Lucas, R.M. Understanding the Relationship between Aboveground Biomass and ALOS PALSAR Data in the Forests of Guinea-Bissau (West Africa). Remote Sensing of Environment 2012, 121, 426-442, doi:10.1016/j.rse.2012.02.012.

7. Champion, I.; Dubois-Fernandez, P.; Guyon, D.; Cottrel, M. Radar Image Texture as a Function of Forest Stand Age. International Journal of Remote Sensing 2008, 29, 1795-1800, doi:10.1080/01431160701730128.

8. Chang, C.-C.; Lin, C.-J. Training V-Support Vector Regression: Theory and Algorithms. Neural computation 2002, 14, 1959-1977.

9. Chen, G.; Hay, G.J. A Support Vector Regression Approach to Estimate Forest Biophysical Parameters at the Object Level Using Airborne Lidar Transects and QuickBird Data. Photogrammetric Engineering \& Remote Sensing 2011, 77, 733-741, doi:10.14358/PERS.77.7.733.

10. Chen, J.M.; Liu, J.; Leblanc, S.G.; Lacaze, R.; Roujean, J.-L. Multi-Angular Optical Remote Sensing for Assessing Vegetation Structure and Carbon Absorption. Remote Sensing of Environment 2003, 84, 516-525, doi:10.1016/S0034-4257(02)00150-5.

11. Chen, L.; Wang, Y.; Ren, C.; Zhang, B.; Wang, Z. Optimal Combination of Predictors and Algorithms for Forest Above-Ground Biomass Mapping from Sentinel and SRTM Data. Remote Sensing 2019, 11, 414, doi:10.3390/rs11040414. 
12. Chopping, M.; Schaaf, C.B.; Zhao, F.; Wang, Z.; Nolin, A.W.; Moisen, G.G.; Martonchik, J.V.; Bull, M. Forest Structure and Aboveground Biomass in the Southwestern United States from MODIS and MISR. Remote Sensing of Environment 2011, 115, 2943-2953, doi:10.1016/j.rse.2010.08.031.

13. Cook, B.; Dubayah, R.; Griffith, P.; Hall, F.G.; Nelson, R.; Ranson, J.; Simard, M.; Siqueira, P.; Strahler, A.H. NACP NEW ENGLAND AND SIERRA NATIONAL FORESTS BIOPHYSICAL MEASUREMENTS: 2008-2010 2011.

14. Cybenko, G. Approximation by Superpositions of a Sigmoidal Function. Mathematics of Control, Signals, and Systems 1989, 2, 303-314, doi:10.1007/BF02551274.

15. Domingues, G.F.; Soares, V.P.; Leite, H.G.; Ferraz, A.S.; Ribeiro, C.A.A.S.; Lorenzon, A.S.; Marcatti, G.E.; Teixeira, T.R.; de Castro, N.L.M.; Mota, P.H.S.; et al. Artificial Neural Networks on Integrated Multispectral and SAR Data for High-Performance Prediction of Eucalyptus Biomass. Computers and Electronics in Agriculture 2020, 168, 105089, doi:10.1016/j.compag.2019.105089.

16. Dube, T.; Mutanga, O. Evaluating the Utility of the Medium-Spatial Resolution Landsat 8 Multispectral Sensor in Quantifying Aboveground Biomass in UMgeni Catchment, South Africa. ISPRS Journal of Photogrammetry and Remote Sensing 2015, 101, 36-46, doi:10.1016/j.isprsjprs.2014.11.001.

17. Eckert, S. Improved Forest Biomass and Carbon Estimations Using Texture Measures from WorldView-2 Satellite Data. Remote Sensing 2012, 4, 810-829, doi:10.3390/rs4040810.

18. Englhart, S.; Keuck, V.; Siegert, F. Aboveground Biomass Retrieval in Tropical Forests - The Potential of Combined X- and L-Band SAR Data Use. Remote Sensing of Environment 2011, 115, 1260-1271, doi:10.1016/j.rse.2011.01.008.

19. Falkowski, M.J.; Gessler, P.E.; Morgan, P.; Hudak, A.T.; Smith, A.M.S. Characterizing and Mapping Forest Fire Fuels Using ASTER Imagery and Gradient Modeling. Forest Ecology and Management 2005, 217, 129-146, doi:10.1016/j.foreco.2005.06.013.

20. Filippi, A.M.; Güneralp, İ.; Randall, J. Hyperspectral Remote Sensing of Aboveground Biomass on a River Meander Bend Using Multivariate Adaptive Regression Splines and Stochastic Gradient Boosting. Remote Sensing Letters 2014, 5, 432-441, doi:10.1080/2150704X.2014.915070.

21. Foody, G.M.; Cutler, M.E.; McMorrow, J.; Pelz, D.; Tangki, H.; Boyd, D.S.; Douglas, I. Mapping the Biomass of Bornean Tropical Rain Forest from Remotely Sensed Data. Global Ecology and Biogeography 2001, 10, 379-387, doi:10.1046/j.1466-822X.2001.00248.x.

22. Freeman, A.; Durden, S.L. A Three-Component Scattering Model for Polarimetric SAR Data. IEEE Transactions on Geoscience and Remote Sensing 1998, 36, 963-973, doi:10.1109/36.673687.

23. Freitas, S.R.; Mello, M.C.S.; Cruz, C.B.M. Relationships between Forest Structure and Vegetation Indices in Atlantic Rainforest. Forest Ecology and Management 2005, 218, 353-362, doi:10.1016/j.foreco.2005.08.036.

24. Friedman, J.H. Stochastic Gradient Boosting. Computational Statistics E Data Analysis 2002, 38, 
367-378, doi:10.1016/S0167-9473(01)00065-2.

25. Ghosh, S.M.; Behera, M.D. Aboveground Biomass Estimation Using Multi-Sensor Data Synergy and Machine Learning Algorithms in a Dense Tropical Forest. Applied Geography 2018, 96, 2940, doi:10.1016/j.apgeog.2018.05.011.

26. Gitelson, A.A.; Merzlyak, M.N. Remote Sensing of Chlorophyll Concentration in Higher Plant Leaves. Advances in Space Research 1998, 22, 689-692, doi:10.1016/S0273-1177(97)01133-2.

27. Gitelson, A.A.; Stark, R.; Grits, U.; Rundquist, D.; Kaufman, Y.; Derry, D. Vegetation and Soil Lines in Visible Spectral Space: A Concept and Technique for Remote Estimation of Vegetation Fraction. International Journal of Remote Sensing 2002, 23, 2537-2562, doi:10.1080/01431160110107806.

28. Gonzalez, P.; Asner, G.P.; Battles, J.J.; Lefsky, M.A.; Waring, K.M.; Palace, M. Forest Carbon Densities and Uncertainties from Lidar, QuickBird, and Field Measurements in California. Remote Sensing of Environment 2010, 114, 1561-1575, doi:10.1016/j.rse.2010.02.011.

29. Güneralp, İ.; Filippi, A.M.; Randall, J. Estimation of Floodplain Aboveground Biomass Using Multispectral Remote Sensing and Nonparametric Modeling. International Journal of Applied Earth Observation and Geoinformation 2014, 33, 119-126, doi:10.1016/j.jag.2014.05.004.

30. Haralick, R.M.; Shanmugam, K.; Dinstein, I. Textural Features for Image Classification. IEEE Transactions on Systems, Man, and Cybernetics 1973, SMC-3, 610-621, doi:10.1109/TSMC.1973.4309314.

31. Hu, T.; Su, Y.; Xue, B.; Liu, J.; Zhao, X.; Fang, J.; Guo, Q. Mapping Global Forest Aboveground Biomass with Spaceborne LiDAR, Optical Imagery, and Forest Inventory Data. Remote Sensing 2016, 8, 565, doi:10.3390/rs8070565.

32. Huang, W.; Sun, G.; Ni, W.; Zhang, Z.; Dubayah, R. Sensitivity of Multi-Source SAR Backscatter to Changes in Forest Aboveground Biomass. Remote Sensing 2015, 7, 9587-9609, doi:10.3390/rs70809587.

33. Huete, A.; Didan, K.; Miura, T.; Rodriguez, E.P.; Gao, X.; Ferreira, L.G. Overview of the Radiometric and Biophysical Performance of the MODIS Vegetation Indices. Remote Sensing of Environment 2002, 83, 195-213, doi:10.1016/S0034-4257(02)00096-2.

34. Jenkins, J.C. Comprehensive Database of Diameter-Based Biomass Regressions for North American Tree Species; United States Department of Agriculture, Forest Service, Northeastern ..., 2004; Vol. $319 ;$

35. Kankare, V.; Vastaranta, M.; Holopainen, M.; Räty, M.; Yu, X.; Hyyppä, J.; Hyyppä, H.; Alho, P.; Viitala, R. Retrieval of Forest Aboveground Biomass and Stem Volume with Airborne Scanning LiDAR. Remote Sensing 2013, 5, 2257-2274, doi:10.3390/rs5052257.

36. Kasischke, E.S.; Bourgeau-Chavez, L.L.; Rober, A.R.; Wyatt, K.H.; Waddington, J.M.; Turetsky, M.R. Effects of Soil Moisture and Water Depth on ERS SAR Backscatter Measurements from an Alaskan Wetland Complex. Remote Sensing of Environment 2009, 113, 1868-1873, doi:10.1016/j.rse.2009.04.006. 
37. Kelsey, K.; Neff, J. Estimates of Aboveground Biomass from Texture Analysis of Landsat Imagery. Remote Sensing 2014, 6, 6407-6422, doi:10.3390/rs6076407.

38. Lu, D. The Potential and Challenge of Remote Sensing-based Biomass Estimation. International Journal of Remote Sensing 2006, 27, 1297-1328, doi:10.1080/01431160500486732.

39. Lucas, R.; Armston, J.; Fairfax, R.; Fensham, R.; Accad, A.; Carreiras, J.; Kelley, J.; Bunting, P.; Clewley, D.; Bray, S.; et al. An Evaluation of the ALOS PALSAR L-Band Backscatter-Above Ground Biomass Relationship Queensland, Australia: Impacts of Surface Moisture Condition and Vegetation Structure. IEEE J. Sel. Top. Appl. Earth Observations Remote Sensing 2010, 3, 576593, doi:10.1109/JSTARS.2010.2086436.

40. Marabel, M.; Alvarez-Taboada, F. Spectroscopic Determination of Aboveground Biomass in Grasslands Using Spectral Transformations, Support Vector Machine and Partial Least Squares Regression. Sensors 2013, 13, 10027-10051, doi:10.3390/s130810027.

41. Maselli, F.; Chiesi, M.; Mura, M.; Marchetti, M.; Corona, P.; Chirici, G. Combination of Optical and LiDAR Satellite Imagery with Forest Inventory Data to Improve Wall-to-Wall Assessment of Growing Stock in Italy. International Journal of Applied Earth Observation and Geoinformation 2014, 26, 377-386, doi:10.1016/j.jag.2013.09.001.

42. Mermoz, S.; Réjou-Méchain, M.; Villard, L.; Le Toan, T.; Rossi, V.; Gourlet-Fleury, S. Decrease of L-Band SAR Backscatter with Biomass of Dense Forests. Remote Sensing of Environment 2015, 159, 307-317, doi:10.1016/j.rse.2014.12.019.

43. Mutanga, O.; Adam, E.; Cho, M.A. High Density Biomass Estimation for Wetland Vegetation Using WorldView-2 Imagery and Random Forest Regression Algorithm. International Journal of Applied Earth Observation and Geoinformation 2012, 18, 399-406, doi:10.1016/j.jag.2012.03.012.

44. Nelson, R.; Margolis, H.; Montesano, P.; Sun, G.; Cook, B.; Corp, L.; Andersen, H.-E.; deJong, B.; Pellat, F.P.; Fickel, T.; et al. Lidar-Based Estimates of Aboveground Biomass in the Continental US and Mexico Using Ground, Airborne, and Satellite Observations. Remote Sensing of Environment 2017, 188, 127-140, doi:10.1016/j.rse.2016.10.038.

45. Otgonbayar, M.; Atzberger, C.; Chambers, J.; Damdinsuren, A. Mapping Pasture Biomass in Mongolia Using Partial Least Squares, Random Forest Regression and Landsat 8 Imagery. International Journal of Remote Sensing 2019, 40, 3204-3226, doi:10.1080/01431161.2018.1541110.

46. Penuelas, J.; Frederic, B.; Filella, I. Semi-Empirical Indices to Assess Carotenoids/Chlorophyll-a Ratio from Leaf Spectral Reflectance. Photosynthetica 1995, 31, 221-230.

47. Phua, M.-H.; Johari, S.A.; Wong, O.C.; Ioki, K.; Mahali, M.; Nilus, R.; Coomes, D.A.; Maycock, C.R.; Hashim, M. Synergistic Use of Landsat 8 OLI Image and Airborne LiDAR Data for AboveGround Biomass Estimation in Tropical Lowland Rainforests. Forest Ecology and Management 2017, 406, 163-171, doi:10.1016/j.foreco.2017.10.007.

48. Ponzoni, F.J.; GalvãO, L.S.; Liesenberg, V.; Santos, J.R. Impact of Multi-Angular CHRIS/PROBA Data on Their Empirical Relationships with Tropical Forest Biomass. International Journal of Remote Sensing 2010, 31, 5257-5273, doi:10.1080/01431160903303005. 
49. Richards, J.; Sun, G.; Simonett, D. L-Band Radar Backscatter Modeling of Forest Stands. IEEE Transactions on Geoscience and Remote Sensing 1987, GE-25, 487-498, doi:10.1109/TGRS.1987.289861.

50. Rodríguez-Veiga, P.; Wheeler, J.; Louis, V.; Tansey, K.; Balzter, H. Quantifying Forest Biomass Carbon Stocks From Space. Current Forestry Reports 2017, 3, 1-18, doi:10.1007/s40725-017-00525.

51. Rouse, J.W.; Haas, R.H.; Schell, J.A.; Deering, D.W. Monitoring Vegetation Systems in the Great Plains with ERTS. NASA special publication 1974, 351, 309.

52. Saatchi, S.; Marlier, M.; Chazdon, R.L.; Clark, D.B.; Russell, A.E. Impact of Spatial Variability of Tropical Forest Structure on Radar Estimation of Aboveground Biomass. Remote Sensing of Environment 2011, 115, 2836-2849, doi:10.1016/j.rse.2010.07.015.

53. Sandberg, G.; Ulander, L.M.H.; Fransson, J.E.S.; Holmgren, J.; Le Toan, T. L- and P-Band Backscatter Intensity for Biomass Retrieval in Hemiboreal Forest. Remote Sensing of Environment 2011, 115, 2874-2886, doi:10.1016/j.rse.2010.03.018.

54. Santi, E.; Paloscia, S.; Pettinato, S.; Fontanelli, G.; Mura, M.; Zolli, C.; Maselli, F.; Chiesi, M.; Bottai, L.; Chirici, G. The Potential of Multifrequency SAR Images for Estimating Forest Biomass in Mediterranean Areas. Remote Sensing of Environment 2017, 200, 63-73, doi:10.1016/j.rse.2017.07.038.

55. Sarker, L.R.; Nichol, J.E. Improved Forest Biomass Estimates Using ALOS AVNIR-2 Texture Indices. Remote Sensing of Environment 2011, 115, 968-977, doi:10.1016/j.rse.2010.11.010.

56. Sharma, R.C.; Hara, K.; Hirayama, H. A Machine Learning and Cross-Validation Approach for the Discrimination of Vegetation Physiognomic Types Using Satellite Based Multispectral and Multitemporal Data. Scientifica 2017, 2017, 1-8, doi:10.1155/2017/9806479.

57. Silleos, N.G.; Alexandridis, T.K.; Gitas, I.Z.; Perakis, K. Vegetation Indices: Advances Made in Biomass Estimation and Vegetation Monitoring in the Last 30 Years. Geocarto International 2006, 21, 21-28, doi:10.1080/10106040608542399.

58. Singh, M.; Evans, D.; Friess, D.; Tan, B.; Nin, C. Mapping Above-Ground Biomass in a Tropical Forest in Cambodia Using Canopy Textures Derived from Google Earth. Remote Sensing 2015, 7, 5057-5076, doi:10.3390/rs70505057.

59. Stephens, P.R.; Kimberley, M.O.; Beets, P.N.; Paul, T.S.H.; Searles, N.; Bell, A.; Brack, C.; Broadley, J. Airborne Scanning LiDAR in a Double Sampling Forest Carbon Inventory. Remote Sensing of Environment 2012, 117, 348-357, doi:10.1016/j.rse.2011.10.009.

60. Wan, R.; Wang, P.; Wang, X. Modeling Wetland Aboveground Biomass in the Poyang Lake National Nature Reserve Using Machine Learning Algorithms and Landsat-8 Imagery. Journal of Applied Remote Sensing 2018, 12, 1, doi:10.1117/1.JRS.12.046029.

61. Widlowski, J.-L.; Pinty, B.; Gobron, N.; Verstraete, M.M.; Diner, D.J.; Davis, A.B. Canopy Structure Parameters Derived from Multi-Angular Remote Sensing Data for Terrestrial Carbon Studies. Climatic Change 2004, 67, 403-415, doi:10.1007/s10584-004-3566-3. 
62. Yu, Y.; Saatchi, S. Sensitivity of L-Band SAR Backscatter to Aboveground Biomass of Global Forests. Remote Sensing 2016, 8, 522, doi:10.3390/rs8060522.

63. Zeng, N.; Ren, X.; He, H.; Zhang, L.; Zhao, D.; Ge, R.; Li, P.; Niu, Z. Estimating Grassland Aboveground Biomass on the Tibetan Plateau Using a Random Forest Algorithm. Ecological Indicators 2019, 102, 479-487, doi:10.1016/j.ecolind.2019.02.023. 